\title{
QUIZ: MASSA PARAVERTEBRAL, QUAL O DIAGNÓSTICO?
}

DOI: $10.5380 /$ rmu.v1i3.40813

Maurício Zapparoli ${ }^{1}$, Dante Luiz Escuissato ${ }^{1}$, Viviane Flumignam Zétola ${ }^{1}$, Gustavo da Cunha Ribas ${ }^{1}$, Diego Schuster Paes ${ }^{1}$

Caso Clínico: Paciente masculino, 57 anos, admitido no PA-HC por quadro de insuficiência respiratória aguda e insuficiência renal aguda. Antecedente de trauma raquimedular há 40 anos, múltiplas fístulas perineais devido a 4 episódios de gangrena de Fournier. Tomografia de tórax demonstrou massa paravertebral.

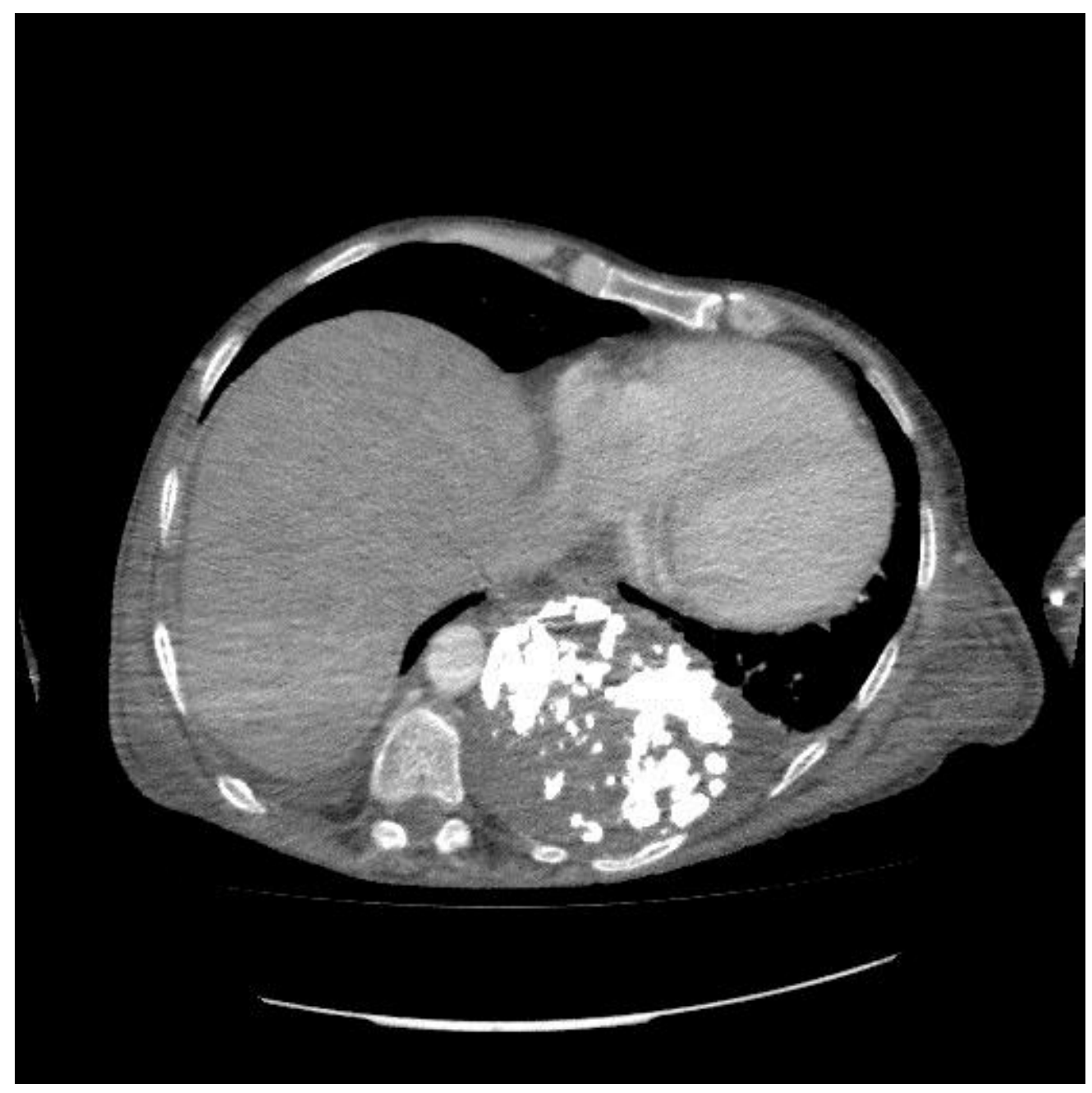
A. Ganglioneuroma
B. Neuroblastoma
C. Paraganglioma
D. Gossipiboma
E. Osteoblastoma 


\section{REVISTA MÉDICA DA UFPR}

\section{RESPOSTA: D) GOSSIPIBOMA}

Gossipiboma é utilizado para designar uma massa formada a partir de uma matriz de algodão (tipicamente uma compressa cirúrgica ou fio não absorvível) circundada por uma reação inflamatória. A palavra é derivada do latim gossypium (algodão) e do kiswahili boma (lugar de dissimular, ocultar) ${ }^{1}$.

Sua incidência varia de 1/5500 a 18760 procedimentos cirúrgicos, sendo mais comum em cirurgias abdominais e de emergência ${ }^{2}$. O tempo para diagnóstico varia entre 1 dia a 40 anos após o procedimento. Pode se apresentar da forma exsudativa, sendo mais precoce e inflamatória, como infecção do sítio operatório; ou da forma fibrinosa, mais tardia, como uma massa de origem de partes moles, com compressão de estruturas locais (pseudotumor) ${ }^{3}$.

O principal exame para identificação é a tomografia computadorizada, demonstrando massa com contornos bem definidos, heterogênea, de baixa densidade, de padrão espongiformes, com calcificações grosseiras ${ }^{4}$.

Principais complicações são a compressão de estruturas adjacentes e a infecção. Se sintomáticos pode ser realizada a remoção cirúrgica, se não, podem ser acompanhados com exames de imagem ${ }^{5}$.

\section{REFERÊNCIAS BIBLIOGRÁFICAS}

1. Martins MCB, Amaral RPG, Andrade CS, et al. Características de imagem na ressonância magnética de gossipiboma intracraniano: relato de caso e revisão da literatura. Radiol Bras. 2009; 42:407-9.

2. Cima RR, Kollengode A, Garnatz J, et al. Incidence and characteristics of potential and actual retained foreign object events in surgical patients. J Am Coll Surg 2008; 207:80.

3. Yildirim S, Tarim A, Nursal TZ, et al. Retained surgical sponge (gossypiboma) after intraabdominal or retroperitoneal surgery: 14 cases treated at a single center. Langenbecks Arch Surg 2006; 391:390.

4. Manzella A, Filho PB, Albuquerque $E$, et al. Imaging of gossypibomas: pictorial review. AJR Am J Roentgenol 2009; 193:S94.

5. Rodrigues D, Perez NE, Hammer PM, Webber JD. Laparoscopic removal of a retained intra-abdominal ribbon malleable retractor after 14 years. J Laparoendosc Adv Surg Tech A 2006; 16:369. 